\title{
Modeling and Simulation of the Anticipated Effects of the Synchronous Condenser on an Electric-Power Network with Participating Wind Plants
}

\author{
Famous O. Igbinovia ${ }^{1, *}$, Ghaeth Fandi ${ }^{1}{ }^{1}$, Ibrahim Ahmad ${ }^{1}$, Zdenek Muller $^{1}$ and \\ Josef Tlusty ${ }^{1,2}$ \\ 1 Department of Electrical Power Engineering, Czech Technical University (CTU) in Prague, Technická 2, \\ Praha 6-Dejvice, 16627 Prague, Czech Republic; fandigha@fel.cvut.cz (G.F.); ahmadibr@fel.cvut.cz (I.A.); \\ zdenek.muller@fel.cvut.cz (Z.M.); tlusty@fel.cvut.cz or tlusty@fbmi.cvut.cz (J.T.) \\ 2 Department of Health Care Disciplines and Population Protection, Faculty of Biomedical Engineering, \\ Czech Technical University in Prague, Sportovců 2311, 27201 Kladno, Czech Republic \\ * Correspondence: igbinfam@fel.cvut.cz or famousigbinovia@yahoo.co.uk; Tel.: +420-731-980-841
}

Received: 29 November 2018; Accepted: 12 December 2018; Published: 18 December 2018

check for

\begin{abstract}
Installing a synchronous condenser (SC) onto an electricity grid can assist in the areas of reactive power needs, short-circuit strength, and, consequently, system inertia and guarantees better dynamic voltage recovery. This paper summarizes the practical potential of the synchronous condenser coordinated in an electric-power network with participating wind plants to supply reactive power compensation and injection of active power at their point of common coupling; it provides a systematic assessment method for simulating and analyzing the anticipated effects of the synchronous condenser on a power network with participating wind plants. A 33-kV power line has been used as a case study. The results indicate that the effect of the adopted synchronous condenser solution model in the MATLAB/Simulink environment provides reactive power, enhances voltage stability, and minimizes power losses, while the wind power plants provide active power support with given practical grid rules.
\end{abstract}

Keywords: active power; reactive power; reactive power compensation; synchronous condensers; wind plants; electric-power network

\section{Introduction}

For most electricity utility companies, ensuring grid reliability, efficiency, and security is a major task. As electric-power grids develop and electrical load profiles change, pressure is being put on electricity transmission and distribution grids, thereby making the need for voltage reinforcement and electric-power grid management much more demanding. Electric-power utility authorities worldwide face many new electricity grid challenges and circumstances, including changes in electric-power production mix, decreases in traditional power production, increases in renewable power production and distributed generation, changes in environmental and regulatory policies, and the retirement of traditional thermal producing stations. These challenges have an operational effect on electric-power infrastructure, particularly bringing about a general inadequacy in reactive power compensation, voltage stability, power system inertia, and low short-circuit strength. As compared with traditional power sources, wind renewable power has a reputation of strong randomness, intermittency, and volatility. It shares the intermittent feature of renewable power sources which are controlled by environmental elements, such as instantaneous changes of weather, that eventually give rise to voltage and frequency instability. Application-related instances prove that connecting wind power 
plants to existing electricity grids has an adverse effect on the security and stable operation of modern electrical power systems [1-5]. High impedance of a fragile or weak electricity grid connection limits the output power of a wind plant operating at unity power factor. This limitation can be reduced by adequately providing high reactive power compensation with the help of synchronous condenser technology. Although it is feasible for Type- 4 wind power plants to produce the requisite reactive power compensation, this technique can appreciably increase the active power rating need and hence reduce the cost of wind power plants and control inverters, since only Type- 3 wind power plants are involved in this instance [6].

Synchronous condensers (SCs) were once generally put to practical use as a means of supplying reactive power compensation to power grids before the introduction of power electronic devices. The benefits of the synchronous condenser solution are that it is a long-standing, well-known, and well-understood technology. It is a very resilient solution, can have high overload capacity, and can provide excellent reactive power support for the grid under low-voltage situations. Synchronous condensers are an origin of short-circuit availability, which can be a significant benefit in weak electric-power grids, and they are not sources of harmonics. The drawbacks of the synchronous condenser include a higher level of losses, slower response time as compared to power electronic devices, and mechanical wear [7-12]. Synchronous condensers have been utilized conventionally in the electric-power industry to support weak electricity grids with poor voltage regulation. Static power electronics equipment, such as static VAR compensators (SVCs) and static synchronous compensators (STATCOMs), are now frequently utilized for reactive power production, and these static power electronics devices provide faster responses [13-15]. Under certain electric-power grid fault circumstances, SCs provide higher reactive power compensation, and, more significantly, the kinetic energy stored in the rotor makes available inertial assistance to the electricity grid during fault conditions [16-19]. The inertia support ability of SCs becomes more significant as the electric-power grid connection needs, such as low-voltage ride-through for distributed generation networks, become stricter and SCs are needed to supply additional services to support electric-power grid stability $[1,20]$. With the continuous growth of the scale of wind power plant inclusion in electrical networks, the interconnection of wind renewable plants with electricity grids has brought remarkable drawbacks for electric-power system dispatching. Apart from the operating situation, wind plants are susceptible to many other factors, such as component faults, weather problems, power system disturbance, etc., that pose a growingly conspicuous threat to power system stability [21-31]. Therefore, active and reactive power assessment methodologies and mechanisms have become a top priority among stakeholders in the electric-power industry.

This research work developed a methodology to generate active power by utilizing the Type- 3 wind plant and reactive power by using the synchronous condenser, particularly on a $33-\mathrm{kV}$ power network. To scrutinize the successfulness of the suggested methodology, it was applied to an interconnected power system with proliferated wind renewable electricity production. This paper should help to put in place strict guidelines for electricity network operators to make better use of synchronous condensers for reactive power generation and the Type- 3 wind plant for active power generation, which will at long last pave the way for further integration of wind power plants into the electricity grid.

The remaining part of this article is organized in the following manner. In Section 2, the vulnerability of the modern grid as a result of high penetration of wind power plants is discussed. In Section 3 , the benchmark case setup of the research is given. This consists of the benchmark line parameters, the benchmark transformer parameters, the benchmark load and three-phase lines parameters, and implementation of the benchmark case using MATLAB/Simulink software. Section 4 explains the methodology used in this study and explores data from the simulation setup. Section 5 presents the mathematical model of the system. Section 6 illustrates a vivid case study, and Section 7 provides the results and discussion of the study case. Conclusions are presented in Section 8. 


\section{Vulnerability of the Modern Grid as a Result of High Penetration of Wind Power Plants}

Independently and in combination, increasing grid voltage instability, reactive power control, short-circuit strength, power system inertia, frequency control, etc., affect the ability of the modern grid to effectively make use of high renewable energy penetration systems such as wind power plants. These also affect the demand for electricity and ability to access, produce, and distribute it. An evaluation of these impacts, both positive and negative, is needed to inform forward-looking endeavors to increase power system security. These effects occur and affect all modern electricity grids and the vulnerabilities faced by various stakeholders in the power industry may vary remarkably depending on their degree of specific exposure to wind renewable power penetration. In general, large-scale wind farms, consisting of many wind power plants, often cover large areas. When wind plants run at nearly full power, the voltage drop of the lines becomes significant [32].

With the increasing share of wind renewable power plants in the present-day electric-power production mix, traditional fossil-fuel-based synchronous generators continue to be substituted from the electric-power production fleet. The high availability of wind power may equally be accountable for the planned retirement of thermal power plants. Nowadays, wind power plants are mostly based on Type- 3 and Type- 4 machine plants. These variable-speed wind plants are decoupled from the corresponding electricity grid by power electronic converters. Different from synchronous generators, some types of wind plants are not able to play a part in frequency control activities such as inertia and governor response after a disturbance [33-37]. Although several control methodologies have been developed to allow Type-3 and Type- 4 wind plants to be used for frequency regulation [38,39], such solutions are still not mandatory and normally do not operate for the Type-3 wind plant. Thus, owing to increased wind production, sustaining enough frequency response has become of vital concern for network operators. Aside from frequency response, short-circuit operation is one more vital issue in power system security owing to higher wind renewable power penetration on the grid [40]. Short-circuit operation is determined by making use of an indicator called the short-circuit ratio (SCR). The short-circuit ratio at the electric-power grid connection point or point of common coupling (PCC) of a wind power plant is defined as the ratio between the short-circuit level at its PCC and the rated efficiency of the wind power plant [41]. A minimal value of SCR at the PCC of a wind power plant is necessary for protection equipment to determine the development of a fault. Owing to the limitation of power electronics efficiency, Type- 3 and Type- 4 wind power plants commonly generate less fault current compared with traditional synchronous generators of equivalent rating [42]. Consequently, the possibility of obtaining undesirable SCR at the PCC of a modern grid with wind plants very much increases for high penetration of wind machines [43]. The insertion of large numbers of wind renewable power plants has changed the robustness of alternating current (AC) grids and made the electric-power grid ineffectual, which is marked by a low SCR or low inertia [44]. SCR is closely associated with voltage stability, so the lower the level the SCR of wind power plants at the PCC, the quicker the response to voltage fluctuation. This leads to instability and, occasionally, to wind plants tripping, resulting in a breakdown of grid stability [45], mostly in situations where a large concentration of wind power plants is joined to a relatively weak electric-power grid [46-48].

It is obvious from the foregoing that, in most situations, frequency response and short-circuit functioning are scrutinized as separate issues. Traditionally, they are individually enhanced when necessary. Regardless, both are related to modern grid security as a result of high wind plant penetration and should be simultaneously considered. Owing to the accumulative entrance of wind power plants on today's modern grids, most thermal power plants may be subjected to planned retirement [49]. These traditional power generators may perhaps be taken out, which would result in a misuse of assets and lead to economic concern. Thus, a second use of these traditional plants could be anticipated in order to achieve some monetary return. For this reason, there is a need for retrofitting a reasonable portion of these synchronous generators into synchronous condensers. As a result of the utilization of new SCs or synchronous generators being retrofitted to SCs and joined to existing electricity substations to provide the required functionality of reactive power compensation, additional 
inertia and short-circuit current are made available to the grid, which in turn improves the security performances of the grid in case of high wind plant generation [43].

\section{Benchmark Case Setup}

The benchmark case setup utilized in this work consists of a commercial medium voltage (MV) distribution network with a substation transformer rating of 50 MVA and a voltage level of $33 \mathrm{kV}$. The MV distribution system has two power lines-L1 and L2-of lengths 30 and $40 \mathrm{~km}$, respectively, connected to it. Figure 1 gives an overview of the benchmark system. A more detailed description of the elements of the system is provided hereafter.

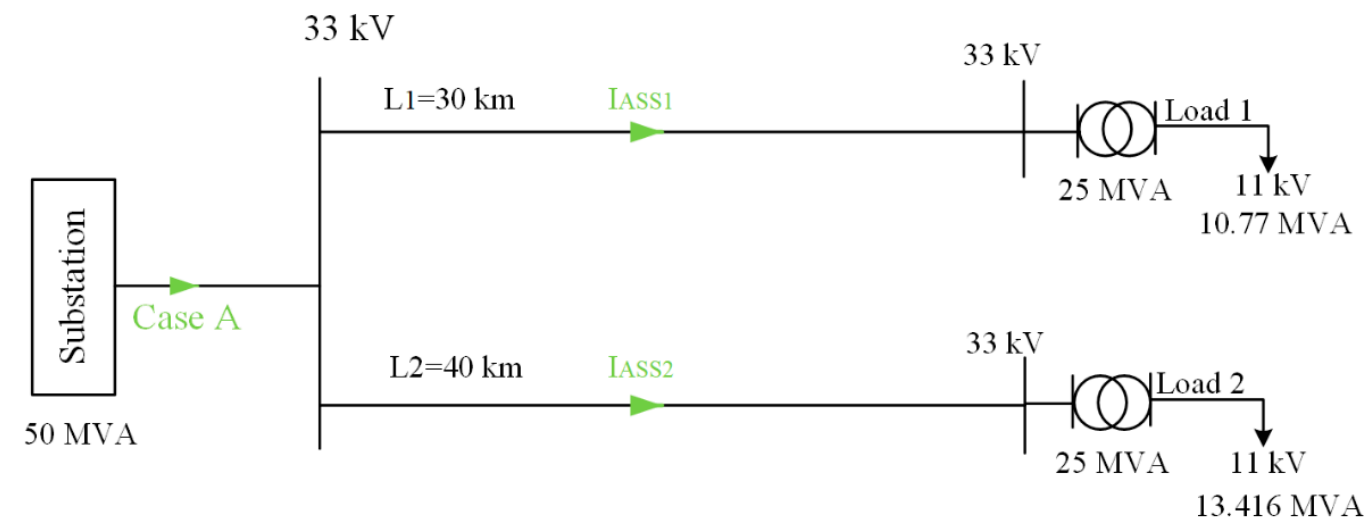

Figure 1. The benchmark system.

\subsection{Benchmark Line Parameters}

The parameters of the power lines are described in detail in Table 1 . Here, it suffices to illustrate the lines main characteristics. Its rated positive resistances $r_{1}(\Omega / \mathrm{km})$, zero-sequence resistances $r_{0}(\Omega / \mathrm{km})$, positive inductances $l_{1}(\mathrm{mH} / \mathrm{km})$, zero-sequence inductances $l_{0}(\mathrm{mH} / \mathrm{km})$, positive capacitances $c_{1}$ $(\mathrm{nF} / \mathrm{km})$, zero-sequence capacitances $c_{0}(\mathrm{nF} / \mathrm{km})$, and frequency $f_{n}(\mathrm{~Hz})$ are the same for both lines. However, the lines' length $(\mathrm{km})$, phase resistance $R_{1}(\Omega)$, phase inductive reactance $X_{1}(\Omega)$, and phase susceptance $B(\mu \mathrm{S})$ vary as presented.

Table 1. Parameters of the medium voltage (MV) commercial electrical power lines.

\begin{tabular}{lcc}
\hline \multicolumn{1}{c}{ Line Number } & $\mathbf{1}$ & $\mathbf{2}$ \\
\hline Positive resistances $r_{1}(\Omega / \mathrm{km})$ & 0.0922 & 0.0922 \\
Zero-sequence resistances $r_{0}(\Omega / \mathrm{km})$ & 0.312 & 0.312 \\
Positive inductances $l_{1}(\mathrm{mH} / \mathrm{km})$ & 0.61 & 0.61 \\
Zero-sequence inductances $l_{0}(\mathrm{mH} / \mathrm{km})$ & 2.83 & 2.83 \\
Positive capacitances $c_{1}(\mathrm{nF} / \mathrm{km})$ & 11.33 & 11.33 \\
Zero-sequence capacitances $c_{0}(\mathrm{nF} / \mathrm{km})$ & 5.01 & 5.01 \\
Frequency $f_{n}(\mathrm{~Hz})$ & 50 & 50 \\
Length $(\mathrm{km})$ & 30 & 40 \\
Phase resistance $R_{1}(\Omega)$ & 2.766 & 3.688 \\
Phase inductive reactance $X_{1}(\Omega)$ & 5.749 & 7.665 \\
Phase susceptance $B(\mu S)$ & 53.39 & 71.19 \\
\hline
\end{tabular}

\subsection{Benchmark Transformer Parameters}

Each power line supplies a 33/11-kV transformer, with a rating of 25 MVA. The parameters of this transformer, detailed in Table 2, show that the frequency $f_{n}(\mathrm{~Hz})$, nominal power $S_{n}(\mathrm{MVA})$, magnetization resistance $R_{m}(\mathrm{M} \Omega)$, and magnetization inductance $L_{m}(\mathrm{H})$ are the same for both transformers, while the connection type, $V_{r m s}(\mathrm{kV}), R(\Omega)$, and $L(\mathrm{H})$ are $\mathrm{D} 11,33,0.15682$, and 0.005808 for the high voltage winding and $\mathrm{Yg}, 11,0.016639$, and 0.00061625 for the low voltage winding. 
Table 2. Parameters of the three-phase 33/11-kV transformers.

\begin{tabular}{|c|c|c|}
\hline TRANSFORMER 1, 2 & High Voltage Winding & Low Voltage Winding \\
\hline Connection type & D11 & $\mathrm{Yg}$ \\
\hline$V_{r m s}(\mathrm{kV})$ & 33 & 11 \\
\hline$R(\Omega)$ & 0.15682 & 0.016639 \\
\hline$L(\mathrm{H})$ & 0.005808 & 0.00061625 \\
\hline Frequency $f_{n}(\mathrm{~Hz})$ & \multicolumn{2}{|c|}{50} \\
\hline Nominal power $S_{n}$ (MVA) & \multicolumn{2}{|c|}{25} \\
\hline Magnetization resistance $R_{m}(\mathrm{M} \Omega)$ & \multicolumn{2}{|c|}{0.06534} \\
\hline Magnetization inductance $L_{m}(\mathrm{H})$ & \multicolumn{2}{|c|}{207.98} \\
\hline
\end{tabular}

\subsection{Benchmark Load and Three-Phase Line Parameters}

Each 25-MVA transformer supplies a consumer load level of $11 \mathrm{kV}$, and the measured values of consumer loads are tabulated in Table 3 . The frequency $f_{n}(\mathrm{~Hz})$ and consumer's voltage $(\mathrm{kV})$ is the same for both loads, but active power $P_{L}(\mathrm{MW})$, reactive power $Q_{L}$ (MVAr), apparent power $S_{L}$ (MVA), and P.F $\cos \left(\varphi_{L}\right)$ vary for both electrical loads. The benchmark three-phase line parameters of the standard power lines that supply the 25-MVA transformer loads are presented in Table 4 . It includes the sending and receiving active power $(P)$, sending and receiving reactive power $(Q)$, sending and receiving voltage $(U)$, and power losses $(\Delta P)$. Table 4 shows that only the sending voltage $\left(U_{s}\right)$ value is the same for both lines, and the other parameters differ.

Table 3. Measured values of consumer loads 1 and 2.

\begin{tabular}{lcc}
\hline \multicolumn{3}{c}{ Parameters Load 1, 2 } \\
\hline Active power $P_{L}(\mathrm{MW})$ & 10 & 12 \\
Reactive power $Q_{L}(\mathrm{MVAr})$ & 4 & 6 \\
Apparent power $S_{L}(\mathrm{MVA})$ & 10.77 & 13.416 \\
P.F $\cos \left(\varphi_{L}\right)$ & 0.928 & 0.894 \\
Frequency $f_{n}(\mathrm{~Hz})$ & 50 & 50 \\
Consumer's voltage $(\mathrm{kV})$ & 11 & 11 \\
\hline
\end{tabular}

Table 4. Measured parameters of the benchmark commercial three-phase lines.

\begin{tabular}{cccccccc}
\hline Line & $\boldsymbol{P}_{\boldsymbol{s}}(\mathbf{M W})$ & $\boldsymbol{P}_{\boldsymbol{r}}(\mathbf{M W})$ & $\boldsymbol{Q}_{\boldsymbol{s}}(\mathbf{M V A r})$ & $\boldsymbol{Q}_{\boldsymbol{r}}(\mathbf{M V A r})$ & $\boldsymbol{U}_{\boldsymbol{s}}(\mathbf{k V})$ & $\boldsymbol{U}_{\boldsymbol{r}}(\mathbf{k V})$ & $\boldsymbol{\Delta} \boldsymbol{P}(\mathbf{M W})$ \\
\hline 1 & 8.929 & 8.673 & 4.237 & 3.814 & 32.570 & 31.077 & 0.256 \\
2 & 10.061 & 9.576 & 6.131 & 5.261 & 32.570 & 30.017 & 0.485 \\
\hline
\end{tabular}

\subsection{Implementation of Benchmark Case in MATLAB/Simulink}

As presented by Figure 1 and then described in Sections 3.1-3.3, only the benchmark parameters were added to the benchmark simulation scheme specifically for this research work and implemented with MATLAB/Simulink software. This benchmark system, which is a standard normal power system network, is referred to as Case A.

\section{Method}

In the suggested approach, the system was modeled by MATLAB/Simulink simulation software. There were three case studies: First was the benchmark case, hereafter referred to as Case A. The second case, or Case B, was when the wind power plant, modeled as Type-3 wind machines, was installed at the main substation of the system for producing active power only and the synchronous condenser was placed at the consumer transformer load ends for reactive power generation. Finally, Case C refers to the situation where the synchronous condenser was placed at the substation for producing reactive power only and the Type-3 wind power plants were placed at the consumer transformer load ends for producing active power only. These arrangements were tested on a 33- $\mathrm{kV}$ power network. 
This methodology was adopted to achieve stability and reduce power losses in the system. This is vividly illustrated in Figures 2 and 3, respectively.

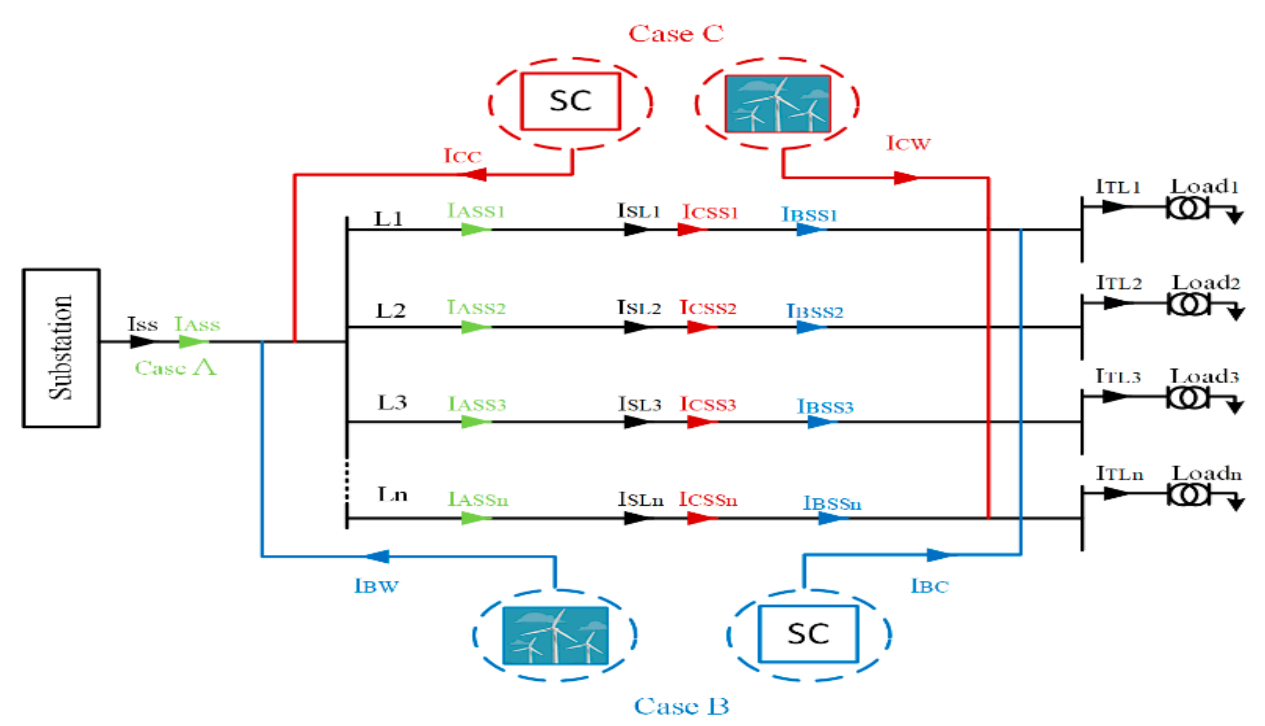

Figure 2. Diagram of the simulation model and methodology scheme of Cases A-C.

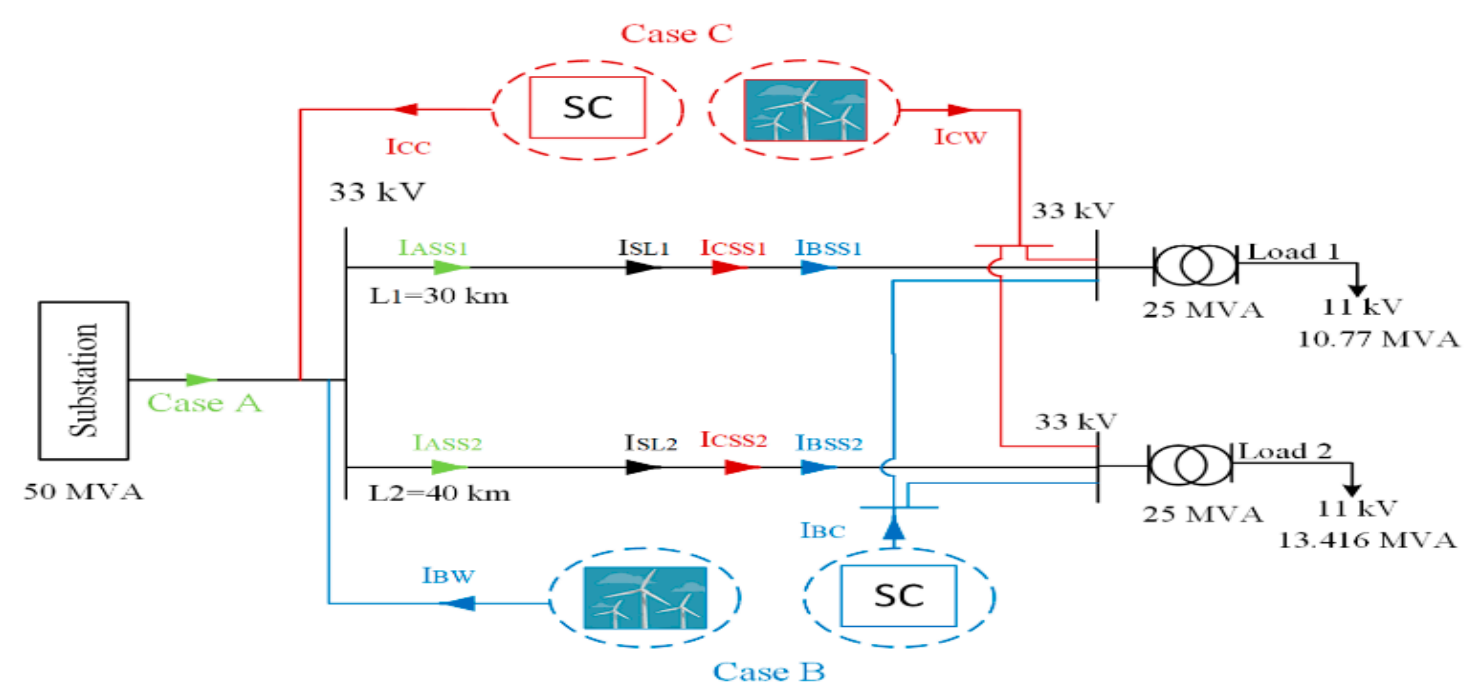

Figure 3. Scheme of the proposed wind plant integrated power system.

\section{Mathematical Model of the System}

Considering the MV substation system $\left(S . S_{1}\right)$ and its vector components:

$$
\begin{gathered}
S_{S S}=\sum_{i=1}^{n} S_{S L i} \\
I_{S S}=\sum_{i=1}^{n} I_{S L i}
\end{gathered}
$$

where:

$S_{S S}$ is the apparent power of the substation system; $I_{S S}$ is the total line current of the substation system; $I_{S L i}$ is the line current supplied to $n$ number of power lines from the substation network; $S_{S L i}$ is the apparent power supplied to $n$ number of power lines from the substation network; 
$i=1,2,3, \ldots \ldots, n$. (i.e., $n$ number of lines).

Hence, for $n$ number of lines that supply $n$ number of loads on the end of the line from the MV substation, the set of transformer and load is equal to the total number of loads. Thus, the total apparent power of each $n$ number of sets is $S_{T L i}$, where $i=1,2,3, \ldots \ldots, n$. (i.e., number of loads). Therefore, line number $=$ each load number.

Hence, in Figure 2,

$$
P_{S L i}=\Delta P_{L L i}+P_{L T i}
$$

where:

$P_{S L i}$ is the active power supplied to $n$ number of lines;

$\Delta P_{L L i}$ is the active power losses of $n$ number of lines;

$P_{L T i}$ is the active power of $n$ number of lines.

From Equation (3):

$$
\Delta P_{L L i}=P_{S L i}-P_{L T i}
$$

The power losses on the line is given by

$$
\Delta P=3 I_{L}^{2} \cdot R_{1 L}
$$

The difference in voltage (voltage drop) of each phase is given by

$$
\Delta V=I_{L} \cdot Z_{L}
$$

Considering Case A only, and from Equation (5) and Figure 2:

$$
\Delta P_{L L i}=3\left(I_{S L i}^{2} \cdot R_{1 L L i}\right) .
$$

Consequently, power losses for $n$ number of lines for Case A will be

$$
\triangle P_{A L L i}=3\left(I^{2}{ }_{A S S i} \cdot R_{1 L L i}\right)
$$

where:

$$
I_{S L i}=I_{A S S i}
$$

$I_{A S S i}$ is the line current for $n$ number of power lines, which equals $I_{S L i}$ for Case A;

$\triangle P_{A L L i}$ is power losses of $n$ number of lines for Case A.

Therefore, the total losses of $S . S_{1}$ for Case A will be

$$
\Delta P_{A T}=\sum_{i=1}^{n} \Delta P_{A L L i}
$$

Similarly, from Equations (6) and (9) and Figure 2:

$$
\Delta V_{A L L i}=I_{A S S n} \cdot Z_{L L i}
$$

where:

$\Delta V_{A L L i}$ is the voltage drop on $n$ number of lines of Case A;

$Z_{L L i}$ is the longitudinal impedance of $n$ number of lines. 
Also, considering Case B, the wind power plants are connected to the bus bar, which supplies all transmission lines, and the synchronous condenser is installed at the end of the MV transmission lines, as shown in Figure 2. Applying Kirchhoff's current law:

$$
I_{B S S}=I_{S S}+I_{B W}-I_{B C}
$$

where:

$I_{B W}$ : wind plant line current;

$I_{B C}$ : synchronous condenser line current;

$I_{B S S}$ : total substation line current of Case B.

From Equation (12) and the vector directions of the wind power plants and synchronous condenser parameters in Figure 2:

$$
I_{B S S i}=I_{S l i}+I_{B W i}-I_{B C i}
$$

where:

$I_{B W i}$ is a constituent of the wind power plant line current going through $n$ number of lines;

$I_{B C i}$ is a constituent of the synchronous condenser line current going through $n$ number of lines;

$I_{B S S i}$ is the new line current supplied to $n$ number of power lines of Case B.

From Equations (5), (12), and (13), the power losses for $n$ number of lines of Case B is written as

$$
\begin{gathered}
\Delta P_{B L L i}=3\left(I^{2}{ }_{B S S i} \cdot R_{1 L L i}\right) \\
\Delta P_{B L L i}=3 \cdot R_{1 L L i}\left(I^{2}{ }_{S L i}+I^{2}{ }_{B W i}+I^{2}{ }_{B C i}+2 \cdot I_{S l i} \cdot I_{B W i}-2 \cdot I_{S l i} \cdot I_{B C i}-2 \cdot I_{B C i} \cdot I_{B W i}\right)
\end{gathered}
$$

where:

$\triangle P_{B L L i}$ is the power losses for $n$ number of lines of Case B.

Therefore, the total losses of $S$. $S_{1}$ for Case B will be

$$
\Delta P_{B T}=\sum_{i=1}^{n} \Delta P_{B L L i} .
$$

Similarly, from Equations (6), (12), and (13) and Figure 2:

$$
\begin{gathered}
\Delta V_{B L L i}=I_{B S S i} \cdot Z_{L L i} \\
\Delta V_{B L L i}=\left(I_{S L i}+I_{B W i}-I_{B C i}\right) \cdot Z_{L L i}
\end{gathered}
$$

where:

$\triangle V_{B L L i}$ is the voltage drop of $n$ number of lines of Case $\mathrm{B}$.

In the same vein, considering Case $C$ :

The synchronous condenser is installed into the bus bar, which supplies power to all sections of the MV transmission lines, and the wind machine is connected to the end of the transmission lines, as shown in Figure 2. Applying Kirchhoff's current law:

$$
I_{C S S}=I_{S S}-I_{C W}+I_{C C}
$$

where:

$I_{C W}$ : wind plant line current;

$I_{C C}$ : synchronous condenser line current;

$I_{C S S}$ : total substation line current of Case C. 
From Equation (19) and the vector directions of the wind power plants and synchronous condenser parameters in Figure 2:

$$
I_{C S S i}=I_{S l i}-I_{C W i}+I_{C C i}
$$

where:

$I_{C W i}$ is a constituent of the wind plants line current going through $n$ number of lines;

$I_{C C i}$ is a constituent of the of synchronous condenser line current going through $n$ number of lines; $I_{C S S i}$ is the new line current supplied to $n$ number of power lines of Case $C$.

From Equations (5), (19), and (20), the power losses for $n$ number of lines of Case $C$ is written as

$$
\begin{gathered}
\Delta P_{C L L i}=3\left(I^{2}{ }_{C S S i} \cdot R_{1 L L i}\right) \\
\Delta P_{C L L i}=3 \cdot R_{1 L L i}\left(I^{2}{ }_{S L i}+I^{2}{ }_{C W i}+I^{2}{ }_{C C i}-2 \cdot I_{S l i} \cdot I_{C W i}+2 \cdot I_{S l i} \cdot I_{C C i}-2 \cdot I_{C C i} \cdot I_{C W i}\right)
\end{gathered}
$$

where:

$\Delta P_{C L L i}$ is the power losses for $n$ number of lines of Case $C$.

Therefore, the total losses of $S . S_{1}$ for Case $C$ will be

$$
\Delta P_{C T}=\sum_{i=1}^{n} \Delta P_{C L L i}
$$

Similarly, from Equations (6), (19), and (20) and Figure 2:

$$
\begin{gathered}
\Delta V_{C L L i}=I_{C S S i} \cdot Z_{L L i} \\
\Delta V_{C L L i}=\left(I_{S L i}-I_{C W i}+I_{C C i}\right) \cdot Z_{L L i}
\end{gathered}
$$

where:

$\Delta V_{C L L i}$ is the voltage drop of $n$ number of lines of Case $\mathrm{C}$.

\section{Case Study}

This section examines the efficacy of the wind power plant and the synchronous condenser. Two operative criteria were utilized: the first was the wind farm's ability to generate active power, and the second was the capability of the synchronous condenser to produce reactive power. The parameters of the wind plant were of the capacity $\mathrm{P}=9 \mathrm{MW}$ and the power factor $=0.9$, and that of the synchronous condenser was $S=3.125 \mathrm{MVA}$. Figure 3 represents the scheme of the proposed wind plant integrated system. The parameters of the benchmark case were applied in the methodology. Values were measured during four steps of load application: the first step was the benchmark case parameters of load values, while steps 2-4 were increased in various percentage values of active, reactive, and apparent power, as presented in Tables 5 and 6 for loads 1 and 2, respectively. The active, reactive, and apparent power values were measured and obtained, as shown in Table 5, for load 1 . The measured parameter values for load 2 are presented in Table 6.

Table 5. Calculated values of reactive, active, and apparent power for various steps for load 1, as stated before in the text.

\begin{tabular}{ccccccc}
\hline Steps & $\begin{array}{c}\text { Active } \\
\text { Power } \\
\boldsymbol{P}_{1}(\mathbf{M W})\end{array}$ & $\begin{array}{c}\text { Rate } \\
\text { Increase } \\
\mathbf{\%} \boldsymbol{P}_{1}\end{array}$ & $\begin{array}{c}\text { Reactive } \\
\text { Power } \boldsymbol{Q}_{1} \\
(\mathbf{M V a r})\end{array}$ & $\begin{array}{c}\text { Rate } \\
\text { Increase \% } \\
\boldsymbol{Q}_{1}\end{array}$ & $\begin{array}{c}\text { Apparent } \\
\text { Power } \boldsymbol{S}_{1} \\
\text { MVA }\end{array}$ & $\begin{array}{c}\text { Rate } \\
\text { Increase \% } \\
\boldsymbol{S}_{1}\end{array}$ \\
\hline 1 & 10 & $0 \%$ & 4 & $0 \%$ & 10.77 & $0 \%$ \\
2 & 12 & $20 \%$ & 5 & $25 \%$ & 13 & $20.71 \%$ \\
3 & 14 & $40 \%$ & 6 & $50 \%$ & 15.232 & $41.43 \%$ \\
4 & 16 & $60 \%$ & 7 & $75 \%$ & 17.464 & $62.15 \%$ \\
\hline
\end{tabular}


Table 6. Calculated values of reactive, active, and apparent power for various steps for load 2, as stated before in the text.

\begin{tabular}{ccccccc}
\hline Steps & $\begin{array}{c}\text { Active } \\
\text { Power } \\
\boldsymbol{P}_{1}(\mathbf{M W})\end{array}$ & $\begin{array}{c}\text { Rate } \\
\text { Increase } \\
\mathbf{\%} \boldsymbol{P}_{1}\end{array}$ & $\begin{array}{c}\text { Reactive } \\
\text { Power } \boldsymbol{Q}_{1} \\
(\mathbf{M V a r})\end{array}$ & $\begin{array}{c}\text { Rate } \\
\text { Increase } \% \\
\boldsymbol{Q}_{1}\end{array}$ & $\begin{array}{c}\text { Apparent } \\
\text { Power } \boldsymbol{S}_{1} \\
\text { MVA }\end{array}$ & $\begin{array}{c}\text { Rate } \\
\text { Increase \% } \\
\boldsymbol{S}_{1}\end{array}$ \\
\hline 1 & 12 & $0 \%$ & 6 & $0 \%$ & 13.416 & $0 \%$ \\
2 & 14 & $16.67 \%$ & 7 & $16.67 \%$ & 15.652 & $16.67 \%$ \\
3 & 16 & $33.33 \%$ & 8 & $33.33 \%$ & 17.889 & $33.33 \%$ \\
4 & 18 & $50 \%$ & 9 & $50 \%$ & 20.125 & $50 \%$ \\
\hline
\end{tabular}

\section{Results and Discussion}

Load 1 simulations were executed at several active power levels of $0 \%, 20 \%, 40 \%$, and $60 \%$, while the reactive power levels were $0 \%, 25 \%, 50 \%$, and $75 \%$ respectively, as depicted in Table 5 . The apparent power levels were $0 \%, 20.71 \%, 41.43 \%$, and $62.15 \%$. For load 2, active, reactive, and apparent power levels were of $0 \%, 16.67 \%, 33.33 \%$, and $50 \%$, implying that the same level of increment was used for the various steps. The percentage of sending voltage deviation from the nominal voltage of $33 \mathrm{kV}$ for different steps in Cases A-C is presented in Figure 4. It shows that the differences between Cases A-C were very small and unremarkable. It also depicts that the load increase in each step brought about an increase in the sending voltage deviation from the nominal voltage value of $33 \mathrm{kV}$. Equally, Figure 5 shows that the deviation of receiving voltage in Cases B and C was lower than that of Case A owing to the power injected onto the grid at the end of the $33 \mathrm{kV} \mathrm{MV}$ transmission lines. It can be noticed that deviations in Cases B and $C$ were very close to each other.

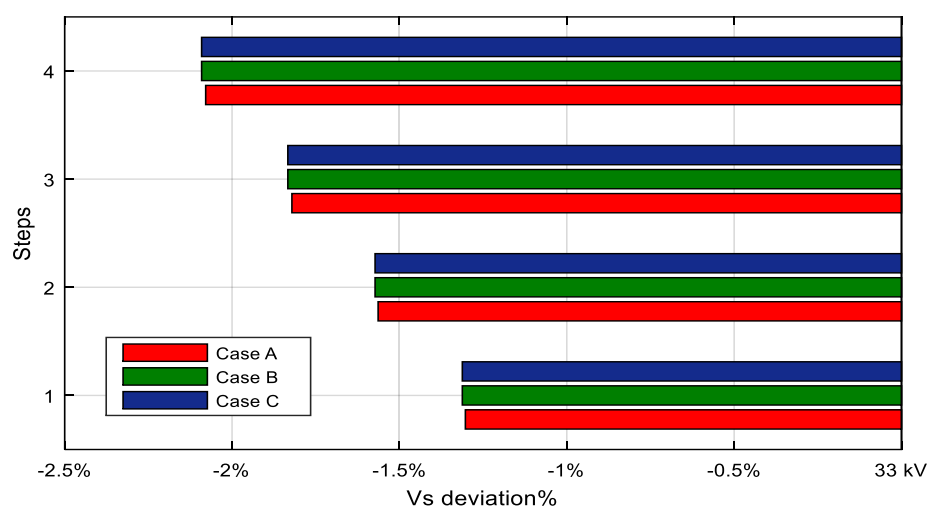

Figure 4. Percentage of sending voltage deviation from the nominal voltage of $33 \mathrm{kV}$ for different steps of Cases A-C.

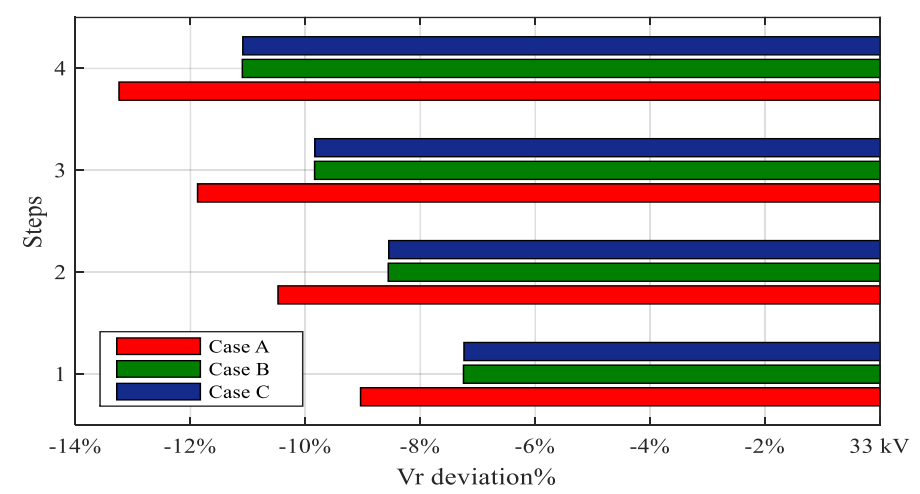

Figure 5. Percentage of receiving voltage deviation from the nominal voltage of $33 \mathrm{kV}$ for different steps in Cases A-C. 
The performance of the wind plant and the synchronous condenser as regards to the percentage of allowed additional voltage drop for different steps in Cases A-C is plotted in Figure 6; it shows that the percentage of allowed additional voltage drops of the lines before the voltage drop exceeded $3.3 \mathrm{kV}$, which is $10 \%$ of the nominal voltage. Here, the maximum allowed voltage drop was $3.3 \mathrm{kV}$, and visibly, the safety margin of Cases B and C was higher than that of Case A. Meanwhile, the achievable voltage drops in steps 3 and 4 did not exceed $3.3 \mathrm{kV}$, going by $1 \%$ for step 3 and $12 \%$ for step 4 . Figure 7 shows the power losses for the different steps in Cases A-C. In this analysis, the power losses for Cases $\mathrm{B}$ and $C$ were lower than that of Case $A$. In addition, power losses in Case B were less than in Case $\mathrm{C}$, which means that using wind power plants to inject active power at the start point of the 33-MV transmission line and the synchronous condenser to produce reactive power at the consumer end of the power line was more effective than what is obtained by the reverse positioning.

From Figure 8, it is observed that the percentage of power loss reductions for different steps in Cases B and C compared with Case A decreased for all cases and steps, but the reduction in Case B was higher. The reduction in all steps was generally the same in each case. The apparent power was the percentage increase in load, and as the load increased, the results became more favorable.

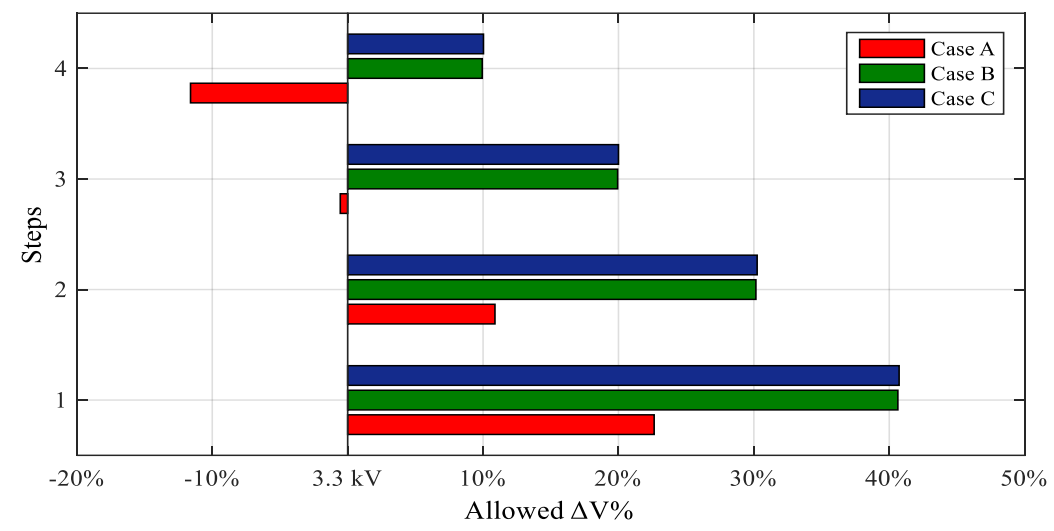

Figure 6. Percentage of allowed additional voltage drop for different steps of Cases A-C.

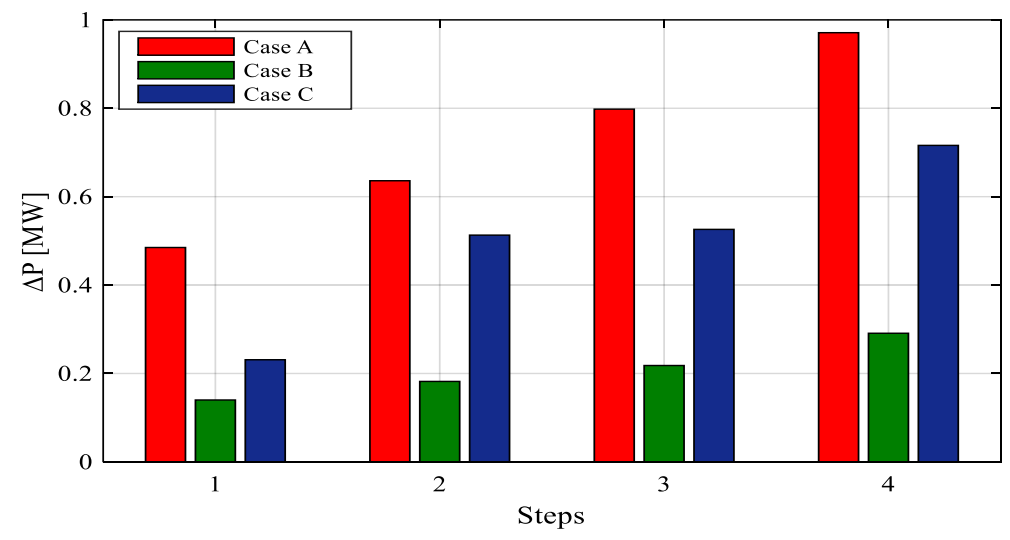

Figure 7. Power losses for different steps in Cases A-C.

The sending power factor for different steps of Cases A-C is plotted in Figure 9. In this analysis, the sending power factor for Cases $\mathrm{B}$ and $\mathrm{C}$ was higher than that of Case A, ranging between 0.97 and 0.93, whereas the result for Case A was between 0.86 and 0.83 . Note that the sending power factor for Case $\mathrm{C}$ was higher than that of Case B. The receiving power factor for different steps of Cases A-C is shown in Figure 10. The result here was like that depicted in Figure 9, where the power factor for Cases B and C was higher than that of Case A. The power factor values recorded for Cases B and C ranged between 0.99 and 0.95 , whereas the values observed for Case A were between 0.88 and 0.87 . Figure 10 shows that the sending power factor of Case $C$ was higher than that of Case $B$. 


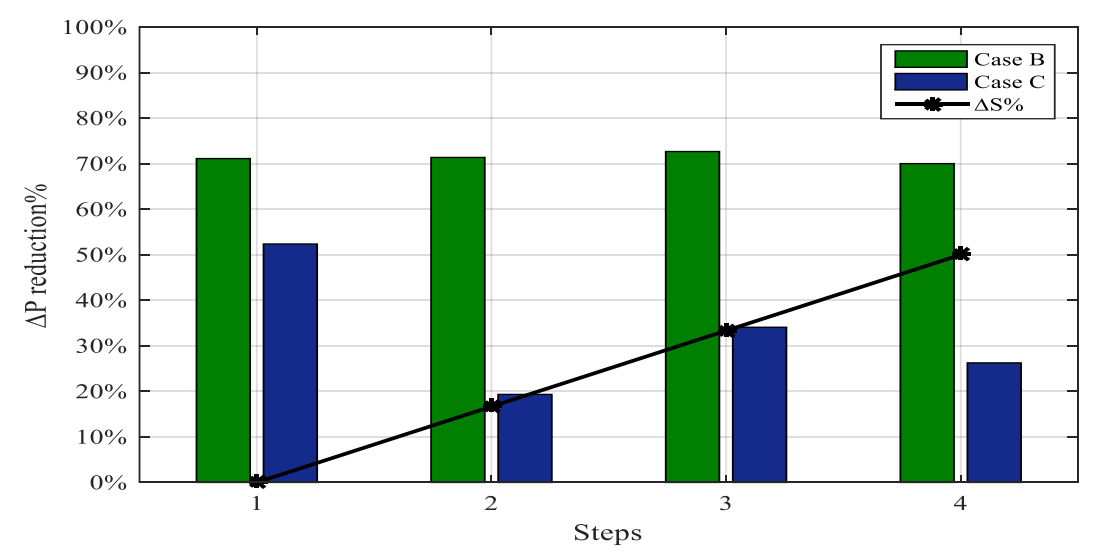

Figure 8. Percentage of power loss reductions for different steps of Cases B and C compared with Case A.

In power systems such as the proposed scheme, active power and a little amount of reactive power is needed. However, with a low power factor, the reactive power is higher than usually needed. A low power factor in the circumstance of Case A implies that reactive power was higher than active power. Hence, a low power factor means dealing with a high amount of reactive power. Therefore, a drawback of having a low power factor is the excessive reactive power. Hence, with a low power factor, the amount of apparent power in the network increases, although the power $(\mathrm{KW})$ is still the same. This results in some significant losses both on the transmission line and on the consumer side, as was the situation for Case A, but the reverse was the situation for Cases B and C, where the losses on both the transmission line and the consumer side of the scheme were minimized due to the installation of the wind plant for active power regulation and the synchronous condenser for reactive power generation. In addition, the voltage drop of the proposed MV transmission lines and distributors increased as the power factor values decreased. In order to keep up with the voltage at the receiving end, Type-3 wind plants for active power control only and synchronous condensers for reactive power control only must be installed into the proposed scheme. The $33-\mathrm{kV}$ transmission line voltage was also maintained owing to the observed power factor standing for both Cases B and C.

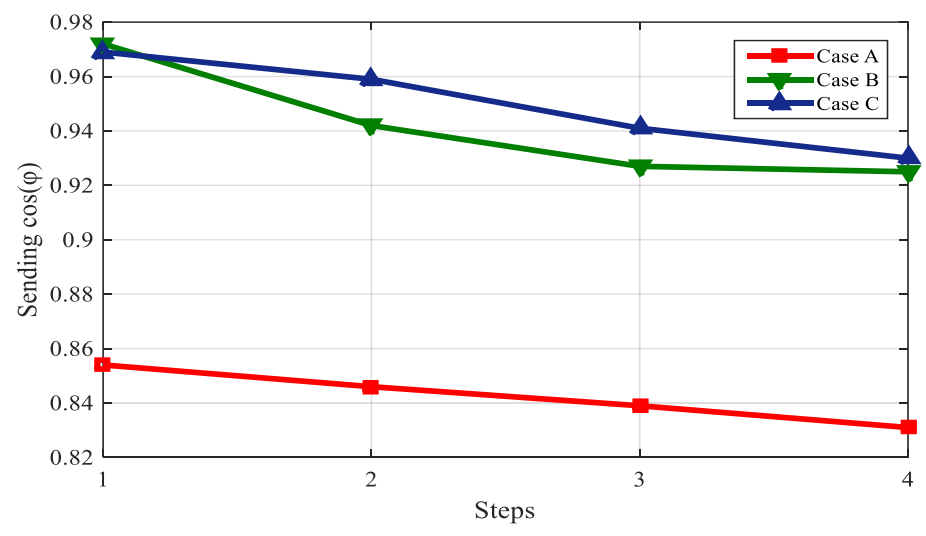

Figure 9. Sending power factor for different steps of Cases A-C.

In Figure 11, the percentage of voltage drop reduction for different steps of Cases B and C is compared with Case A. It is vividly clear that the voltage drop was reduced in Cases B and C as compared with Case A and the performance of the various case situations was the same for all steps. Additionally, the percentage of reduction of voltage drop was approximately the same for all steps (that is, 20\%) but with a corresponding small decrease as we moved from steps 1 to 4 . On the contrary, for Case A, the percentage of voltage drop steadily increased as we moved from steps 1 to 4 . A voltage drop performance analysis was required to ensure that the end of the power lines had enough power 
to drive the final load. The issue of voltage drop only gets worse as more loads are connected onto the power lines. As the length of power lines increases or as the current increases, so does the voltage drop. Note that leaving some margin for future loads will ensure that electricity consumers get a reliable power system as expected. The resulting measured and modeled percentage of voltage drop and power loss reductions for different steps in Cases B and C compared with Case A is graphically illustrated in Figure 12. It shows the general comparison of Cases B and C with Case A, where it was observed that the methodologies used in Cases B and C were better than that used in Case A. Results for Cases B and C showed the same performance of voltage drop, which was about $20 \%$. However, regarding the power losses on the proposed scheme, Case B showed better performance than Case C. The loss reduction for Case B was about $70 \%$ but was $50 \%$ for Case C. Overall, the performance of Case $B$ is seen to be the best case situation observed.

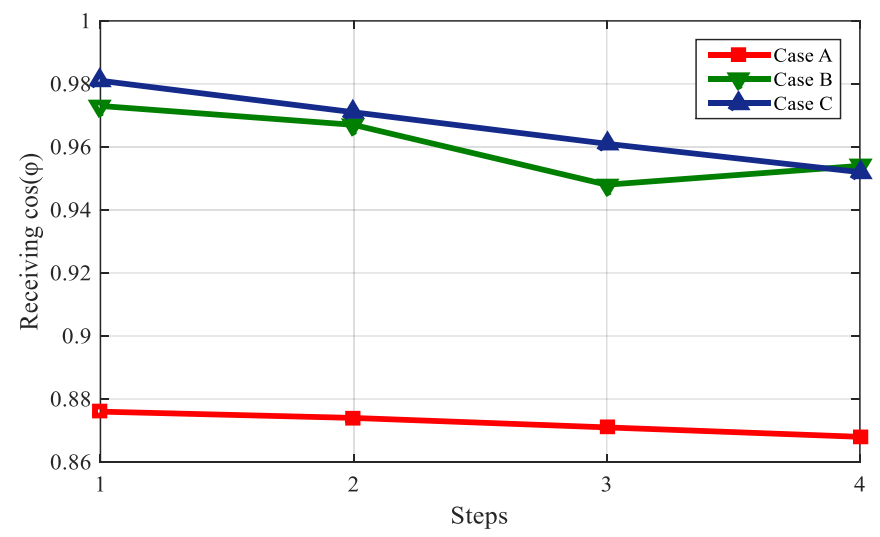

Figure 10. Receiving power factor for different steps of Cases A-C.

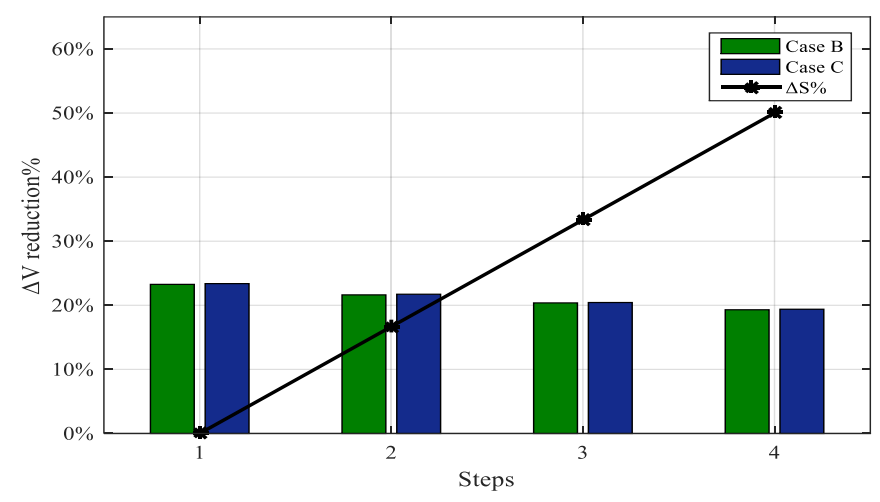

Figure 11. Percentage of voltage drop reduction for different steps of Cases B and C compared with Case A.

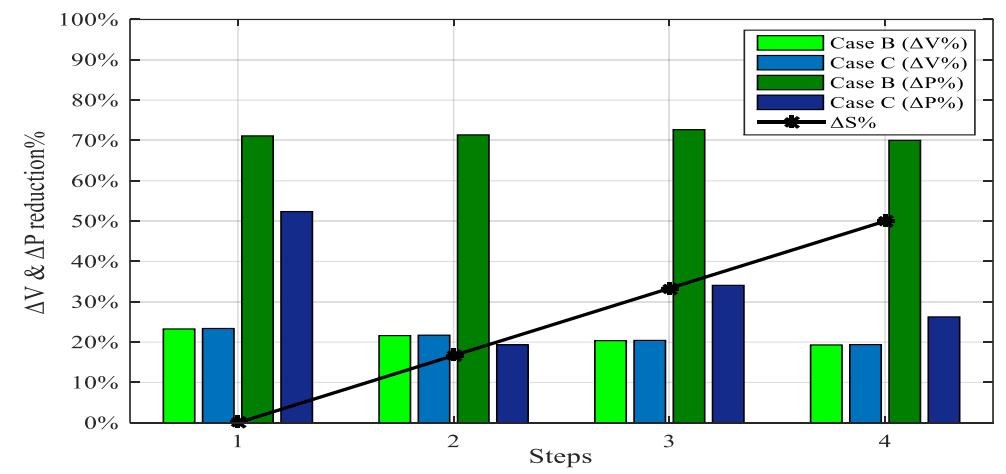

Figure 12. Percentage of voltage drop and power loss reduction for different steps in Cases B and C compared with Case A. 


\section{Conclusions}

From the analysis of a normal power system, it was observed that when additional generation sources of active and reactive power were spread along the network, the proposed scheme attained stability. Conclusively, in a traditional power system, like that of Case A in the design model, the limitation of increasing load creates issues for the regulation of voltage level and this brings about an increase in the voltage drop of the MV power line, sometimes more than the allowed ratio of $10 \%$ from nominal voltage value, which also increases power losses. All of these issues cause instability, power losses, and are harmful to loads. In this model, the Type-3 renewable wind power plant was used to generate active power and the synchronous condenser to produce reactive power by choosing different points on the proposed scheme to separately connect both the wind renewable source and the synchronous condenser. The network was stabilized and power losses were equally reduced, even when the loads increased, implying that the proposed scheme can absorb more load. Hence, it can be posited that the Type-3 wind plant and the synchronous condenser scheme is economical. It is worth mentioning that the proposed technique of this paper can be applied to different load deployments in any power system in order to establish stability to preserve the acceptable security performances of electricity grids. This research paper establishes an effective application of synchronous condenser technology for the deployment of reactive power and the wind power plant for the deployment of active power in a modern electricity scheme. This methodology could effectively simulate the effect of an anticipated synchronous condenser on a power grid with participating wind plants, thereby generating useful information for managers, engineers, and researchers in the electricity industry. This information can improve modern electricity growth plans and can be used to formulate new electricity development strategies and action plans. It is important for electricity managers to develop management strategies and development plans that allow electricity resources to be utilized more effectively in a sustainable manner. It aids in improving power system security by providing adequate active and reactive power for the stability of the electricity grid and the minimization of power system losses. Therefore, the proposed methodology is likely to bring significant technical and financial benefits to power system operators.

Author Contributions: This study represents the combination of work from five authors. F.O.I. performed the research, analyzed the data, and wrote the paper, G.F. and I.A. interpreted the results, Z.M. directed the write-up, while J.T. revised and approved the final manuscript.

Funding: This research was funded by the Grant Agency of the Czech Technical University in Prague (grant No. SGS 17/181/OHK3/3T/13).

Acknowledgments: We would like to thank the anonymous reviewers for their careful reading of our manuscript and their insightful comments.

Conflicts of Interest: The authors declare no conflict of interest.

\section{References}

1. Hsu, P.; Muljadi, E. Permanent magnet synchronous condenser for wind power plant grid connection support. In Proceedings of the IEEE 9th International Conference on Power Electronics and ECCE Asia (ICPE-ECCE Asia), Seoul, Korea, 1-5 June 2015; pp. 362-366.

2. Ernst, B.; Oakleaf, B.; Ahlstrom, M.L. Predicting the wind. Power Energy Mag. 2007, 11, 79-89.

3. Scarlatache, F.; Grigoras, G. Influence of wind power plants on power systems operation. In Proceedings of the International Conference and Exposition on Electrical and Power Engineering, Iasi, Romania, 16-18 October 2014; pp. 1010-1014.

4. Shin, S.; Oh, J.; Jang, S.; Cha, J.; Kim, J. Active and Reactive Power Control of ESS in Distribution System for Improvement of Power Smoothing Control. J. Electr. Eng. Technol. 2017, 12, 1007-1015. [CrossRef]

5. Wang, J.; Fang, K.; Pang, W.; Sun, J. Wind Power Interval Prediction Based on Improved PSO and BP Neural Network. J. Electr. Eng. Technol. 2017, 12, 989-995. [CrossRef] 
6. Cui, W.; Yan, W.; Lee, W.; Zhao, X.; Ren, Z.; Wang, C. A Two-stage Stochastic Programming Model for Optimal Reactive Power Dispatch with High Penetration Level of Wind Generation. J. Electr. Eng. Technol. 2017, 12, 53-63. [CrossRef]

7. Deecke, A.; Kawecki, R. Usage of existing power plants as synchronous condenser. Przeglad Elektrotechniczny 2015, 91, 64-66. [CrossRef]

8. Marken, P.E.; Henderson, M.; LaForest, D.; Skliutas, J.; Roedel, J.; Campbell, T. Selection of synchronous condenser technology for the granite substation. In Proceedings of the IEEE PES Transmission and Distribution Conference and Exposition, New Orleans, LA, USA, 19-22 April 2010; pp. 1-6.

9. Skliutas, J.; LaForest, D.; D'Aquila, R.; Derr, D.; Kronbeck, E. Next-generation synchronous condenser installation at the VELCO granite substation. In Proceedings of the IEEE Power \& Energy Society General Meeting, Calgary, AB, Canada, 26-30 July 2009; pp. 1-8.

10. Igbinovia, F.O.; Fandi, G.; Švec, J.; Müller, Z.; Tlustý, J. Comparative review of reactive power compensation technologies. In Proceedings of the IEEE 16th International Scientific Conference on Electric Power Engineering (EPE), Kouty nad Desnou, Czech Republic, 20-22 May 2015; pp. 2-7.

11. Igbinovia, F.O.; Fandi, G.; Muller, Z.; Tlusty, J. Progressive Usage of the Synchronous Machine in Electrical Power Systems. Indian J. Eng. 2018, 15, 117-126.

12. Dusane, P.M.; Dang, M.; Igbinovia, F.O.; Fandi, G. Analysis of the Synchronous Machine in its Operational Modes: Motor, Generator and Compensator. In Proceedings of the 19th International Student Conference on Electrical Engineering, (CD-ROM), Prague, Czech Republic, 16-18 May 2015; ISBN 978-80-01-05728-5. Available online: radio.feld.cvut.cz (accessed on 5 November 2018).

13. Kojori, H.A.; Dewan, S.B.; Lavers, J.D. A large-scale PWM solid-state synchronous condenser. IEEE Trans. Ind. Appl. 1992, 28, 41-49. [CrossRef]

14. Ganjefar, M.F.S. Comparing SVC and Synchronous Condenser Performacnee in Mitigating Torsional Oscillations, International Transactions on Electrical Energy Systems; Wiley Online Library: Hoboken, NJ, USA, 2014.

15. Sengar, A.S.; Chhajer, R.; Fandi, G.; Igbinovia, F.O. Comparison of the Operational Theory and Features of SVC and STATCOM. In Proceedings of the 19th International Student Conference on Electrical Engineering, (CD-ROM), Prague, Czech Republic, 16-18 May 2015; ISBN 978-80-01-05728-5. Available online: radio.feld. cvut.cz (accessed on 6 November 2018).

16. Igbinovia, F.O.; Fandi, G.; Müller, Z.; Švec, J.; Tlusty, J. Cost implication and reactive power generating potential of the synchronous condenser. In Proceedings of the IEEE 2nd International Conference on Intelligent Green Building and Smart Grid (IGBSG), Prague, Czech Republic, 27-29 June 2016.

17. Igbinovia, F.O.; Fandi, G.; Müller, Z.; Švec, J.; Tlustý, J. Optimal location of the synchronous condenser in electric-power system networks. In Proceedings of the IEEE 17th International Scientific Conference on Electric Power Engineering (EPE), Prague, Czech Republic, 16-18 May 2016.

18. Teleke, S.; Abdulahovic, T.; Thiringer, T.; Svensson, J. Dynamic performance comparison of synchronous condenser and SVC. IEEE Trans. Power Deliv. 2008, 23, 1606-1612. [CrossRef]

19. Mendis, N.; Muttaqi, K.; Perera, S. Management of battery supercapacitor hybrid energy storage and synchronous condenser for isolated operation of PMSG-based variable-speed wind turbine generating systems. IEEE Trans. Smart Grid 2014, 5, 944-953. [CrossRef]

20. Igbinovia, F.O.; Fandi, G.; Müller, Z.; Tlusty, J. Reputation of the Synchronous Condenser Technology in Modern Power Grid. In Proceedings of the 11th International Conference on Power System Technology (POWERCON), Guangzhou, China, 6-8 November 2018.

21. Wu, H.; Guo, J.; Ding, M. Reliability Evaluation of a Distribution System with wind Turbine Generators Based on the Switch-section Partitioning Method. J. Electr. Eng. Technol. 2016, 11, 575-584. [CrossRef]

22. Qiao, W.; Yang, X.; Gong, X. Wind Speed and Rotor Position Sensorless Control for Direct-Drive PMG Wind Turbines. IEEE Trans. Ind. Appl. 2012, 48, 3-11. [CrossRef]

23. Li, S.H.; Haskew, T.A.; Swatloski, R.P.; Gathings, W. Optimal and Direct-Current Vector Control of Direct-Driven PMSG Wind Turbines. IEEE Trans. Power Electr. 2012, 27, 2325-2337. [CrossRef]

24. Yang, H.J.; Xie, K.G.; Tai, H.M.; Chai, Y. Wind Farm Layout Optimization and Its Application to Power System Reliability Analysis. IEEE Trans. Power Syst. 2016, 31, 2135-2143. [CrossRef]

25. Dobakhshari, A.S.; Firuzabad, M.F. A Reliability Model of Large Wind Farms for Power System Adequacy Studies. IEEE Trans. Energy Conver. 2009, 25, 792-801. (In Chinese) [CrossRef] 
26. Fandi, G.; Ahmad, I.; Igbinovia, F.O.; Muller, Z.; Tlusty, J.; Krepl, V. Voltage Regulation and Power Loss Minimization in Radial Distribution Systems via Reactive Power Injection and Distributed Generation Unit Placement. Energies 2018, 11, 1399. [CrossRef]

27. Fandi, G.; Igbinovia, F.O.; Tlustý, J.; Mahmoud, R. Voltage Regulation and Power Losses Reduction in a Wind Farm Integrated MV Distribution Network. J. Electr. Eng. Bratisl. Slovak. 2018, 69, 85-92. [CrossRef]

28. Fandi, G.; Igbinovia, F.O.; Ahmad, I. Reactive power producing capability of wind turbine systems with IGBT power electronics converters. Indian J. Eng. 2018, 15, 198-208.

29. Fandi, G.; Igbinovia, F.O.; Ahmad, I.; Svec, J.; Muller, Z. Modeling and Simulation of a Gearless Variable Speed Wind Turbine System with PMSG. In Proceedings of the IEEE PES-IAS Power Africa Conference, Accra, Ghana, 27-30 June 2017; pp. 59-64.

30. Fandi, G.; Igbinovia, F.O.; Švec, J.; Müller, Z.; Tlustý, J. Advantageous Positioning of Wind Turbine Generating System in MV Distribution Network. In Proceedings of the IEEE 17th International Scientific Conference on Electric Power Engineering (EPE), Prague, Czech Republic, 16-18 May 2016.

31. Fandi, G.; Igbinovia, F.O.; Müller, Z.; Švec, J.; Tlusty, J. Using Renewable Wind Energy Resource to Supply Reactive Power in Medium Voltage Distribution Network. In Proceedings of the IEEE 16th International Scientific Conference on Electric Power Engineering (EPE), Kouty nad Desnou, Czech Republic, 20-22 May 2015.

32. Liu, P.; Li, Z.; Zhuo, Y.; Lin, X.; Ding, S.; Khalid, M.; Adio, O.S. Design of Wind Turbine Dynamic Trip-off Risk Alarming Mechanism for Large-scale Wind Farms. IEEE Trans. Sustain. Energy 2017, 8, 1668-1678. [CrossRef]

33. Ma, R.; Qin, Z.; Yang, W.; Li, M. Research on Voltage Stability Boundary under Different Reactive Power Control Mode of DFIG Wind Power Plant. J. Electr. Eng. Technol. 2016, 11, 1571-1581. [CrossRef]

34. Kaloi, G.S.; Wang, J.; Baloch, M.H. Dynamic Modeling and Control of DFIG for Wind Energy Conversion System Using Feedback Linearization. J. Electr. Eng. Technol. 2016, 11, 1137-1146. [CrossRef]

35. Xia, J.; Dyśko, A.; O’Reilly, J. Future stability challenges for the UK network with high wind penetration levels. IET Gener. Transm. Distrib. 2015, 9, 1160-1167. [CrossRef]

36. Tianyu, W.; Guojie, L.; Yu, Z.; Chen, F. Damping for Wind Turbine Electrically Excited Synchronous Generators. J. Electr. Eng. Technol. 2016, 11, 801-809. [CrossRef]

37. Wang, C.; Liu, X.; Liu, H.; Chen, Z. A Fault Diagnostic Method for Position Sensor of Switched Reluctance Wind Generator. J. Electr. Eng. Technol. 2016, 11, 29-37. [CrossRef]

38. Attya, A.B.T.; Hartkopf, T. Control and quantification of kinetic energy released by wind farms during power system frequency drops. IET Renew. Power Gener. 2013, 7, 210-224. [CrossRef]

39. Žertek, A.; Verbic, G.; Pantos, M. A novel strategy for variable-speed wind turbines' participation in primary frequency control. IEEE Trans. Sustain. Energy 2012, 3, 791-799. [CrossRef]

40. Masood, N.; Yan, R.; Saha, T.K.; Piekutowski, M. Correlation between frequency response and short-circuit performance due to high wind penetration. In Proceedings of the IEEE Power and Energy Society General Meeting, Denver, CO, USA, 26-30 July 2015; pp. 1-5.

41. Zhang, Y.; Huang, S.; Schmall, J.; Conto, J.; Billo, J.; Rehman, E. Evaluating system strength for large-scale wind plant integration. In Proceedings of the IEEE Power and Energy Society General Meeting, National Harbor, MD, USA, 27-31 July 2014; pp. 1-5.

42. IEEE Joint Working Group. Fault Current Contributions from Wind Plants. Available online: http:/ / www. pes (accessed on 7 November 2018).

43. Masood, A.N.; Yan, R.; Saha, K.T.; Bartlett, S. Post-retirement utilisation of synchronous generators to enhance security performances in a wind dominated power system. IET Gener. Transm. Distrib. 2016, 10, 3314-3321. [CrossRef]

44. IEEE Guide for Planning DC Links Terminating at AC Locations Having Low Short-Circuit Capacities. IEEE Stdu. Tech. Rep. 1997, 1204-1997. [CrossRef]

45. Neumann, T.; Feltes, C.; Erlich, I. Response of DFG-based wind farms operating on weak grids to voltage sags. In Proceedings of the IEEE Power Energy Society General Meeting, Detroit, MI, USA, 24-29 July 2011; pp. 1-6. 
46. Xing-wei, X.; Gang, M.; Guang-hui, S.; Hong-peng, Z.; Kai-yuan, H.; De-bin, G.; Jia-qi, T.; Xin, M.; Yong, X. The problems and solutions for large-scale concentrated integration of wind power to partially weak regional power grid. In Proceedings of the International Conference on Sustainable Power Generation and Supply, Nanjing, China, 6-7 April 2009; pp. 1-6.

47. Peng, D.; Yiying, Z.; Chong, L.; Tao, H.; Weiwei, W. The impact of LVRT characteristic on the stability of northwest China grid with large scale wind power. In Proceedings of the Renewable Power Generation Conference (RPG), Beijing, China, 9-11 September 2013.

48. Hong, M.; Xin, H.; Liu, W.; Xu, Q.; Zheng, T.; Gan, D. Critical Short Circuit Ratio Analysis on DFIG Wind Farm with Vector Power Control and Synchronized Control. J. Electr. Eng. Technol. 2016, 11, 320-328. [CrossRef]

49. AEMO. Integrating Renewable Energy-Wind Integration Studies Report. 2013. Available online: http: / / www.aemo.com.au (accessed on 9 November 2018).

(C) 2018 by the authors. Licensee MDPI, Basel, Switzerland. This article is an open access article distributed under the terms and conditions of the Creative Commons Attribution (CC BY) license (http://creativecommons.org/licenses/by/4.0/). 